\title{
CALCULATION OF INVERTER POWER CLIPPING LOSS DUE TO PV ARRAY OVERSIZING
}

\author{
Satish Pandey, Rajesh Kumar, Kapil Panwar \\ Department of Analytics, Mahindra Susten Pvt. Ltd. India
}

\begin{abstract}
The paper presents a method for calculation of Inverter power clipping loss due to $P V$ array oversizing or high DC to AC ratio. For calculation, a PV plant installed in southern region of India having $D C$ to $A C$ ratio 1.4 was selected. Since a PV plant runs at full load in peak hours only (i.e. 11 am to $2 \mathrm{pm}$ ) when the irradiance level is $\geq$ $1000 \mathrm{~W} / \mathrm{m}^{2}$, which results in inverter power clipping (InPC) whereas at lower irradiance the produced PV power is also low which will not lead inverter power clipping. The high DC to AC ratio, increases the generation at lower irradiation but when the irradiance is high i.e. $\geq 1000 \mathrm{~W} / \mathrm{m}^{2}$, the inverter limits the input DC power and hence the inverter power also limited as per rated capacity of inverter. Hence the power generated by oversized PV array is lost at high irradiance and termed as Inverter power clipping loss. The significance of calculation of clipping loss is to optimize the inverter DC to AC ratio \& also to estimate the guaranteed PV plant $P R$ (performance ratio) as due to clipping loss the PV plant PR drops \& it leads misinterpretation to observer as low performance of $P V$ plant. If clipping loss is added to the observed $P R$, then the actual PR will rise to meet the expected PR.

Hence the paper presents the method to calculate the simulated power as per expected $P V$ plant $P R \&$ irradiance to provide the inverter power clipping loss.

Keywords: PV Plant, Oversizing, power, Clipping loss, Simulated power, irradiance, PR, Generation

Cite this Article: Satish Pandey, Rajesh Kumar, Kapil Panwar, Calculation of Inverter Power Clipping Loss Due to PV Array Oversizing, International Journal of Electrical Engineering \& Technology, 10(4), 2019, pp. 43-46.

http://iaeme.com/Home/issue/IJEET?Volume $=10 \&$ Issue $=4$
\end{abstract}

\section{INTRODUCTION}

Solar PV power plants are increasing in number, at the same time for revenue/generation gain system designers are increasing the $\mathrm{DC} / \mathrm{AC}$ ratio (i.e. $\mathrm{DC}>\mathrm{AC}$ ). This increased $\mathrm{DC} / \mathrm{AC}$ ratio (1:1 to $1.5: 1$ (normally) helps in generating higher units of electricity at lower irradiation also.

[1] This introduces a new challenge as when irradiance is high i.e. more than $1000 \mathrm{~W} / \mathrm{m}^{2}$ (which is standard rating). The inverter effectively prevents the system from reaching its [maximum power point], capping the power at the inverter's nameplate power rating. ${ }^{[2]}$ 
This design limitation is mainly to prevent IGBT stack failure, as it has its own current carrying limits. Hence at any time when power generated by PV modules is higher than the allowable input-power limit of the inverter, Inverters starts clipping the power. For this period when PV modules are capable of delivering higher output, but this power is not utilized due to a design limitation of inverter considered as a loss \& known as inverter power clipping loss.

Challenge is that in current scenario inverter is neither generating any alarm/notifications to intimate about clipping nor it provides the losses occurred due to clipping. This clipping loss is predicted by several prediction models such as PVsyst, Plant Predict \& SAM etc. but in real as described above this clipping is directly proportional with power generated by PV modules (input power to the inverter) and that is depending upon irradiance $\left(\mathrm{W} / \mathrm{m}^{2}\right.$ ) level during peak hours [generally 11:00 am to $2: 00 \mathrm{pm}$ ]. So, the challenge is to calculate real time energy losses occurred due to power clipping by PV inverter.

Estimation of clipping loss is useful in designing of judicious DC/AC ratio of PV plant \& estimation of guaranteed PR for PV plant.

\section{PERFORMANCE RATIO (PR)}

The performance ratio is a measure of the quality of a PV plant that is independent of the plant location and it therefore, often described as a quality factor. The performance ratio (PR) is stated as percent and describes the relationship between the actual and theoretical energy outputs of the PV plant. It thus shows the proportion of the energy that is actually available for export to the grid after deduction of energy loss (e.g. due to thermal losses and conduction losses) and of energy consumption for operation.

The real time actual PR of the plant based on the SACDA data can be obtained by:

$$
P R=\frac{P \times I_{S T C}}{G T I \times C}
$$

Where,

PR - Actual Performance Ratio

GTI - Irradiance on the inclined Surface, W/m2

P - Power Output, W

$\mathrm{I}_{\mathrm{STC}}$ - Irradiance at STC, $1000 \mathrm{~W} / \mathrm{m} 2$

C - DC capacity of Plant, W

The closer the PR value determined for a PV plant approaches $100 \%$, the more efficiently the respective PV plant is operating. In real life, a value of $100 \%$ cannot be achieved, as unavoidable losses always arise with the operation of the PV plant (e.g. thermal loss due to heating of the PV modules).

\section{STEPS FOR CALCULATION INVERTER POWER CLIPPING LOSS}

For calculation of clipping loss following steps are followed.

\subsection{Identification of clipping event}

It is well understood that the clipping shall be there when output is limited by the maximum Inverter capability to generate power. For Inverters having flat Temperature vs Power Curve, nearly constant maximum Inverter output could be observed. Inverter Clipping Losses can be expected to happen under the condition of Inverter operating at an output power near to the maximum power generating capacity coupled with PR starting to drop. The logic to detect the presence of Inverter Clipping is shown in equation below.

If $\left(\mathrm{P}>=\right.$ Inv Max \& $\left.\mathrm{PR}_{\mathrm{t}}<\mathrm{PR}_{\mathrm{t}-1}\right)$ 
Then $\mathrm{CS}=1$

Else $\mathrm{CS}=0$

Where,

CS - Clipping Status (0- No Clipping, 1 - Clipping)

Inv Max - Maximum Inverter Power,

$\mathrm{PR}_{\mathrm{t}}=\mathrm{PR}$ at any time instant

$\mathrm{PR}_{\mathrm{t}-1}=\mathrm{PR}$ at previous time instant

Using the above logic, determination of occurrence of clipping can be done and calculation for Inverter Clipping Losses can be initiated.

\subsection{Projected PR}

Projected PR is average PR of PR at the time instant at which clipping starts \& PR at the time instant at which clipping ends.

$\mathrm{PR}_{1}=\mathrm{PR}$ if $\left(\mathrm{CS}_{\mathrm{t}}=1 \& \mathrm{CS}_{\mathrm{t}-1}=0\right)$

$\mathrm{PR}_{2}=\mathrm{PR}$ if $\left(\mathrm{CS}_{\mathrm{t}}=0 \& \mathrm{CS}_{\mathrm{t}-1}=1\right)$

Projected $\mathbf{P R}=$ Average $\left(\mathbf{P R}_{\mathbf{1}}, \mathbf{P R}_{2}\right)$

\subsection{Simulated Power}

Using the calculated value of Projected PR (as described in the previous section), the simulated power of the inverter shall be calculated. The simulated power is the theoretical power value which could have been achieved had there been no clipping. The Equation for determining the simulated power is described below.

Simulated Power $=$ Projected PR $\times C \times G_{T} I_{t}(\mathrm{~kW})$

\subsection{Inverter clipping loss}

The theoretical calculated Clipping Loss shall be the difference of the Simulated power and the Actual power of the inverter.

Inverter clipping loss $=$ Simulated power - Actual power $(k W)$

Loss in generation/ Energy $(\mathrm{kWh})$ can be calculated from instantaneous loss in power due to clipping by standard power to energy conversion formula.

\section{RESULTS}

Using methodology defined a sample calculation is being done for a central inverter of $750 \mathrm{~kW}$ and results are as:

Table 1 Clipping Loss Result

\begin{tabular}{|c|c|c|c|c|c|c|}
\hline $\begin{array}{c}\text { Actual } \\
\text { Energy } \\
\text { (kwh) }\end{array}$ & $\begin{array}{c}\text { Actual } \\
\text { PR (\%) }\end{array}$ & $\begin{array}{c}\text { Simulated } \\
\text { Energy } \\
\text { (kWh) }\end{array}$ & $\begin{array}{c}\text { Simulated } \\
\text { PR (\%) }\end{array}$ & $\begin{array}{c}\text { Loss in } \\
\text { Energy } \\
\text { due to } \\
\text { clipping } \\
\text { (kWh) }\end{array}$ & $\begin{array}{c}\text { \% Loss in } \\
\text { Energy due } \\
\text { to Clipping } \\
\text { (\%) }\end{array}$ & $\begin{array}{c}\text { Confidence } \\
\text { Interval }\end{array}$ \\
\hline 5159.2 & $72.70 \%$ & 5209.5 & $73.41 \%$ & -50.32 & $-0.98 \%$ & $95 \%$ \\
\hline
\end{tabular}




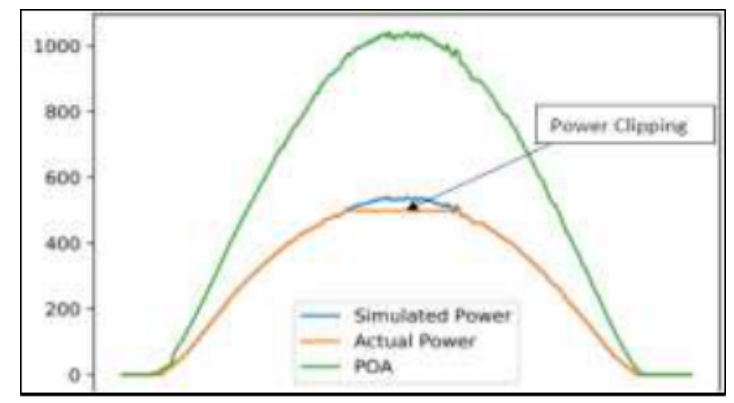

Figure 1 Inverter power clipping curve

Here in the above curve POA, Simulated Power \& Actual Power is represented, whereas the flat curve (in orange color) shows the actual clipped power at inverter output. The clipping loss is the areas enclosed between actual power \& simulated power. Table-1 shows data of daily energy and simulated energy with loss in energy due to presence of clipping.

\section{CONCLUSION}

The above method can be used for calculation of inverter clipping loss with $\pm 2 \%$ accuracy \& $95 \%$ confidence interval. The clipping loss is the loss which will occur at high $\mathrm{DC} / \mathrm{AC}$ ratio. Since the High DC/AC ratio is beneficial at low irradiance, hence to avoid the clipping losses will not be wise decision. In near future such techniques can be developed that at the instant of clipping loss the loss cam be utilized to charge the batteries \& it can be utilized to supply the auxiliary consumption in night time.

\section{LIMITATION}

The clipping loss calculation in above method depends upon POA data, which is measured using pyranometer (Solar irradiation sensor) which have its own accuracy of measurement. This will have an impact on clipping loss calculation. As per good industry practice secondary class pyranometer is used so there may be maximum $2 \%$ deviation in POA with respect to actual POA.

\section{REFERENCES}

[1] SMA, "7 reasons why you should oversize your PV array," Dec. 2015. [Online]. Available: http://en.sma-sunny.com/en/7-reasons-whyyou-should-oversize-your-pv-array2/

[2] Solar Power World Why array oversizing makes financial sense By Kathie Zipp February 12, 2018

[3] Lov Kumar Mishra, Avanish K Tiwari and Krishan K Pandey, A Comparative Assessment of Energy Management System and Strategies in Kanpur City of Uttar Pradesh: A Bottom up Distributed Generation Approach, International Journal of Advanced Research in Management (IJARM), Volume 5, Issue 4, July-August (2014), pp. 32-47.

[4] Sreedevi Prasanna and Vijayakumar Narayanan. A Novel Approach for Generation of AllOptical OFDM Using Discrete Cosine Transform Based on Optical Couplers in a RadioOver-Fiber Link. International Journal of Advanced Research in Engineering and Technology, 8(3), 2017, pp 43-49.

[5] Dr. Sudhir Sharma, Dr. Chintu Rza and Amanpreet Kaur, Interline UPQC Connected with PV Array for Better Power Quality: International Journal of Electrical Engineering \& Technology, 9(3), 2018, pp. 137-145. 